\title{
Leaders
}

\section{The role of the pathologist in human rights abuses}

\author{
Jørgen L Thomsen
}

\begin{abstract}
The objective and unbiased statement is much valued in international work against human rights abuses. Pathologists play an increasingly important role. In this article, this role is illustrated by examples and the international set of rules is described. It is emphasised that under no circumstances should physicians assist in procedures, such as torture, which can weaken a human being. There is ongoing research into the sequelae of torture, both by gross and microscopic examination and in the living and dead victims. (F Clin Pathol 2000;53:569-572)
\end{abstract}

Keywords: torture; human rights; death in custody

Ethical questions play a role in every branch of medicine. This is also the case in pathology. Although ethical questions arise in daily work, they become much more conspicuous in situations of armed conflict, in repressive regimes, or in countries with corrupt police or military forces. The pathologist has a role in cases of suspicious death. In the following article an attempt will be made to define this role. The distinction between hospital pathologists and forensic pathologists is not upheld. The forensic pathologist might be faced with ethical dilemmas more often, because of the work for the police. In many areas of the world, however, there is no forensic profession, and the hospital pathologist will have to perform necropsies in cases of death in custody, etc.

\section{International rules}

The World Medical Association (WMA) have taken an active part in preventing physicians from taking part in human rights violations and in the protection of those who are under threat. " In the "Declaration of Geneva" (WMA, 1948, 1968, and 1983) it is stated that: "I will maintain the utmost respect for human life from its beginning even under threat and I will not use my medical knowledge contrary to the laws of humanity". This statement in itself excludes any participation, active or passive, in torture.

In "Regulations in time of armed conflict" (WMA, 1956, 1957, and 1983) it is said that: "The primary task of the medical profession is to preserve health and save life. Hence it is deemed unethical for physicians to ... weaken the physical or mental strength of a human being without therapeutic justification".

"The declaration of Tokyo" (WMA, 1975) has played a central role in the prevention of the medical doctor's participation in torture. It was the first international rule aimed directly at the medical profession and it gave a definition of torture that has been widely used since. In this declaration any participation in torture is prohibited, including: the provision of "any premises, instruments, substances or knowledge to facilitate the practice of torture or other forms of cruel, inhuman or degrading treatment". National medical associations and fellow doctors are encouraged to support the doctor in the face of threats or reprisals resulting from a refusal to condone the use of torture or any other form of cruel, inhuman, or degrading treatment. This was stressed again in the "Hamburg declaration" (WMA, 1997) in which the WMA "reiterates and reaffirms the responsibility of the organised medical profession". It is encouraged "to teach and investigate in all schools of medicine and hospitals the consequences of torture and its treatment, the rehabilitation of the survivors, the documentation of torture, and the professional protection described in this statement". The WMA declarations are not legally binding but retaliations can take the form of striking off from the medical board. International conventions - for example, by the United Nations (UN), might be legally binding if ratified by the individual country and included in the national legislation.

Physicians as human rights abusers There are numerous examples of physicians who have violated the rules and have either participated actively in torture or have covered up the signs of torture in both living and dead victims..$^{2-5}$ Their motives have varied from direct participation because of a conviction that they were helping the society against "subversives" to fear of reprisals. Pathologists working for the authorities belong to the group of "doctors at risk", together with physicians working in prisons or military camps. The pathologist typically runs the risk when he is asked to examine a case of death in custody. The authorities may directly or indirectly send a message saying that they want a conclusion of natural death. It is then tempting to forget to mention - for example, the many fractured ribs caused by repeated blows or kicks, and instead to emphasise the resulting bronchopneumonia. 
Table 1 Physical torture methods

Beating or kicking Whipping (flogging) Phalanga

Burns

Electricity

Suspension

Belana

Asphyxiation

Extraction or fracture of teeth Tight rope or chain

Food deprivation

Dehydration

Chili, gasoline, etc in wounds

Sexual torture

Anal torture

Administration of drugs

Shaking

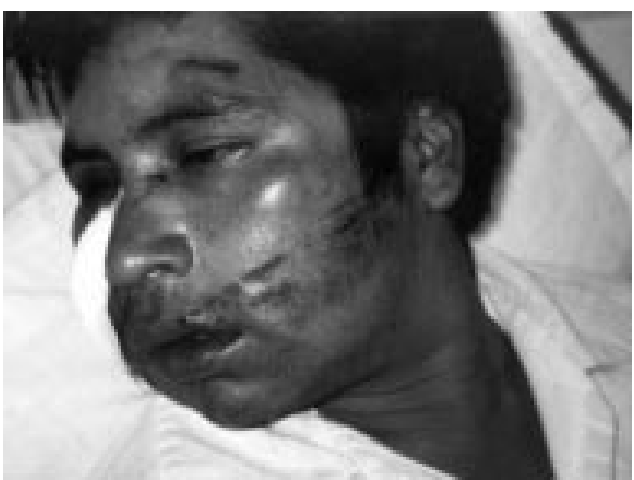

Figure 1 Young man with recent bruises and excoriations on the face, consistent with beating with a stick (Chiapas, Mexico).

\section{Documentation of physical torture in the living}

Documentation in the living is usually performed by clinicians. The pathologist, however, might well become involved, especially if biopsies are taken of recent or old lesions.

Table 1 lists some of the more common types of physical torture.

The various forms of blunt violence such as beating and kicking might leave unspecific lesions or may result in a recognisable pattern (fig 1). There may be haematomas, ecchymoses, excoriations, contusion wounds, or even fractures (for example, of the ribs) and with a distribution indicating violence from other persons. It is frequently important to be able to state the (lack of) probability that the traumatic lesions were caused by the victim himself because this is often claimed by the accused. Another important aspect is the age of the lesions. The examiner will usually have to rely upon his judgment and experience. A biopsy of the lesion might be helpful but is usually not permissible because it is for a diagnostic purpose without a therapeutic aim. In addition, it is not often possible to examine

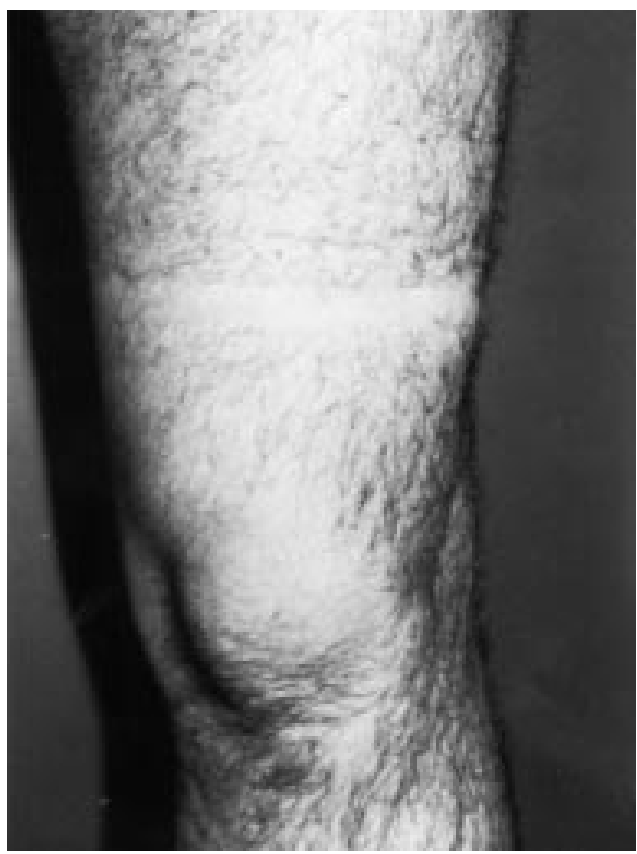

Figure 2 Localised alopecia caused by a tight rope. ${ }^{6}$

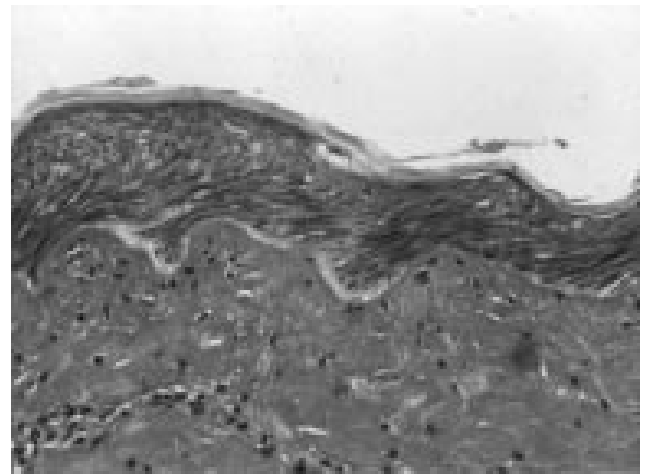

Figure 3 "Streaming" of nuclei in the epidermis as a result of heat.

torture victims with recent lesions because they are usually kept in custody until the lesions have healed. There may then only remain scars, or even no skin changes at all; however, scars can still be informative (fig 2). ${ }^{6}$ Lesions caused by flogging can be characteristic in the healed state, because they show a double contoured, straight, or curved pattern and may heal with hyperpigmented margins. Phalanga is the beating of the soles of the feet, often for many hours, resulting in severe swelling of the feet as a result of haemorrhage and oedema. The resulting condition may last for years and require intensive physiotherapy. Burns are often easily recognisable, even after some time. If a biopsy is available there might be typical epidermal heat changes (fig 3), also seen as a result of electrical lesions. In the latter type of lesion it is often possible to demonstrate characteristic changes in both the epidermis, the dermis, and the subcutis (fig 4).$^{7-9}$ The lesions are segmented with deposition on the surface of metals such as copper or iron. In the epidermal cells there may be vesicular nuclei in the first few days and in the deeper tissues calcifications that will remain for a couple of months. Belana is a type of torture first described in $1994 .{ }^{10} \mathrm{~A}$ pole is placed on top of the victim, who is lying on his back. The pole is pressed down with great weight and rolled up over the body. There may be crushing of the muscles with release of myoglobin and subsequent kidney failure. In dental torture an odontologist is necessary for the exact evaluation of the lesions, which should include radiography. Many torture victims spend months or even years as prisoners with insufficient intake

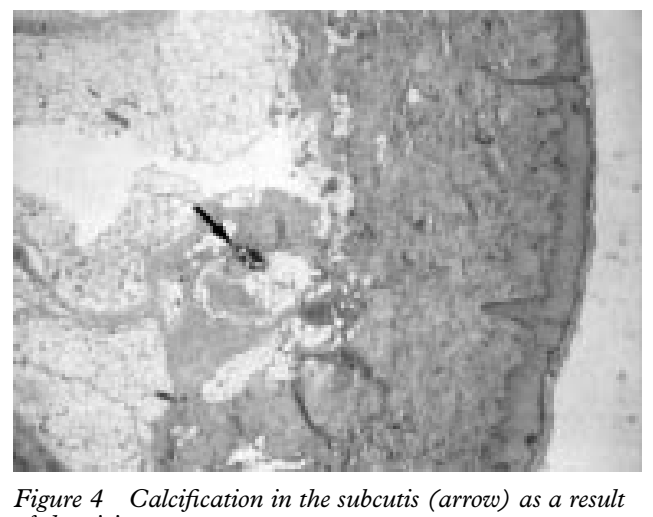
of electricity. 


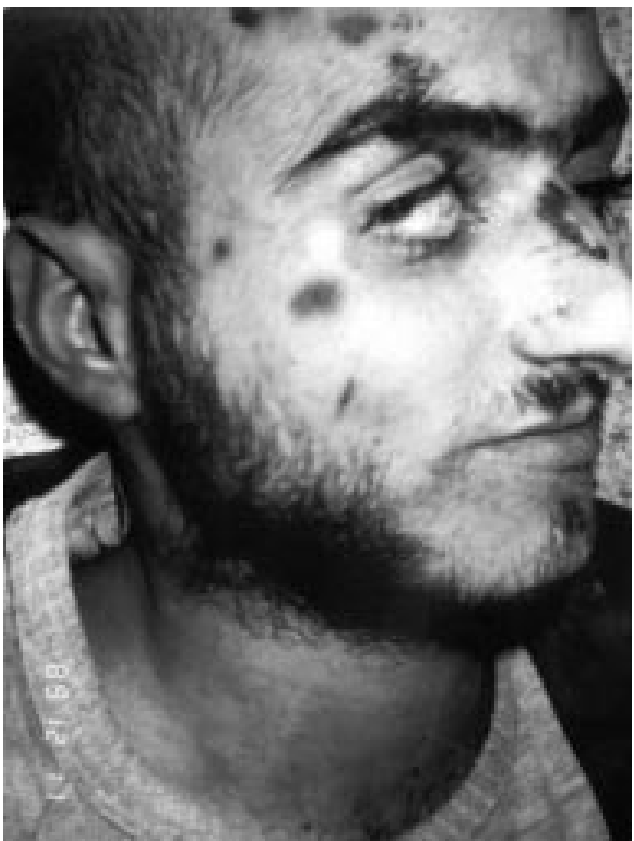

Figure 5 Death in custody. Recent excoriations - torture?

of food, and it is important to estimate their general health, including vitamin deficiencies, which might be revealed in skin changes. In sexual and anal torture there may be damage to the internal organs. There are thus examples of perforation of the bowel caused by the insertion of various types of objects into the rectum. The administration of drugs may serve the purpose of reducing resistance or inducing confusion and anxiety. The diagnosis is best made by toxicological analyses. Recently, it has been shown that shaking-best known in shaken infant syndrome-is used as a torture method even in adults. ${ }^{11}$ It can result in life threatening lesions such as a subdural haematoma.

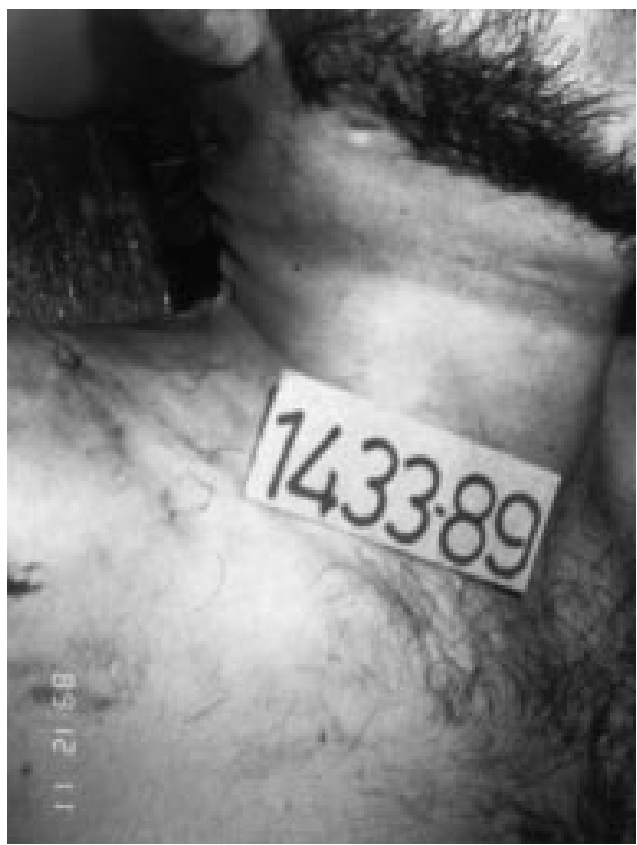

Figure 6 Same case as fig 5. After partial removal of the beard a suspension mark is seen on the neck, probably as a result of suicidal hanging.

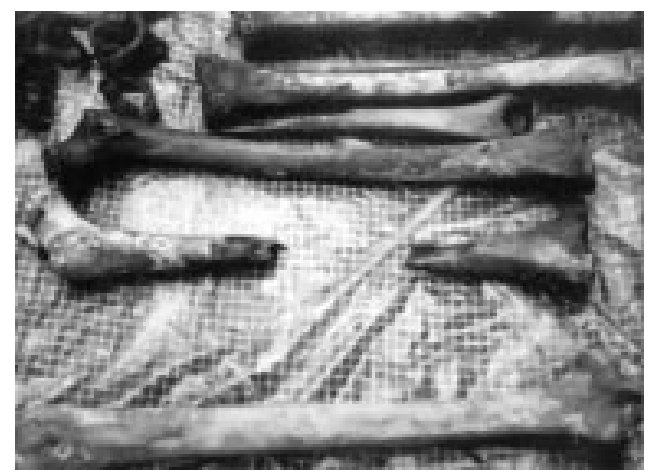

Figure 7 Bones from victims of extrajudicial killing after three months in water in a tropical climate (The Philippines).

\section{Death in custody}

In cases of death in police custody or in a prison there will always arise a suspicion of death as a result of physical abuse, and indeed this has often been the case. In 1991 the UN produced a "Manual on the effective prevention and investigation of extra-legal, arbitrary and summary executions". This manual contains a model necropsy protocol and guidelines for cases suspicious of authority abuse. Even obvious cases of suicide may have been preceded by torture (figs 5 and 6). It is the obligation of the pathologist to describe the lesions objectively and to state his conclusions truthfully. The report should go to the proper authorities. If, however, these are the abusing parties, then international help must be sought, for instance from the WMA.

\section{Exhumations}

The world has been witness to many mass graves and recently even the UN has taken an active part in the exhumation of victims of extrajudicial killings, for instance in civil wars or in extreme authoritarian regimes. In

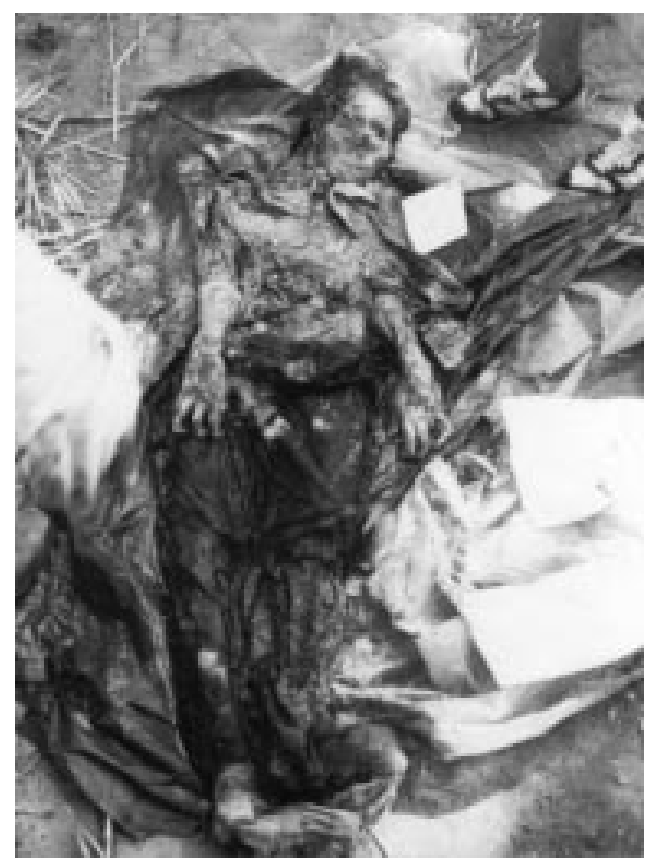

Figure 8 Victim of extrajudicial killing after three months in a grave (El Salvador). 


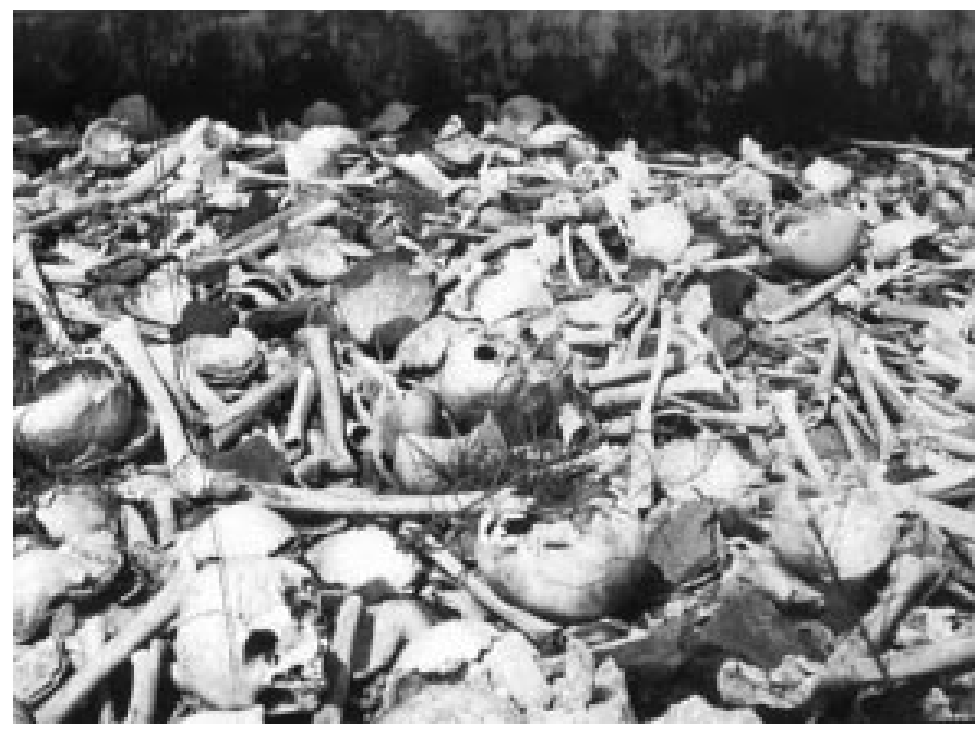

Figure 9 "Killing field" (Cambodia).

Argentina during the military dictatorship of 1976-83, thousands of alleged subversives were killed, and afterwards many of the victims were exhumed. In exhumations a combination of archaeological, anthropological, and forensic methods is applied. ${ }^{12}$ The main task is usually to identify the body/skeleton and to establish the cause and manner of death. It is also useful to determine the time of death, and it has become increasingly clear that the rate of deterioration and the subsequent state of the exhumed body depend on many different factors of which only some are known-for example, humidity, temperature, clothing, scavengers, the composition of the soil, and the time of year when buried (fig 7). Experimental research has been undertaken to estimate the postmortem interval. ${ }^{13}$ The UN is engaged in the exhumation of mass graves in Bosnia, Croatia, and Rwanda. There have been several exhumations of individual graves or graves with a small number of victims (figs 8 and 9). ${ }^{14}$ In this work, the experienced pathologist may play an important role, even in skeletonised victims. It is an area in which cooperation between different professions and the application of new methods are essential. Molecular methods have been used increasingly in the identification procedure-for example, comparing the DNA profiles of the victim with those of the alleged family members.

\section{Knowledge is prevention}

Knowledge as a result of documentation may have a preventive effect on human rights abus- ers. Scientific reports from a pathologist will embarrass the authorities and might even destabilise the political structure. International bodies, financial aid organisations, or commerce partners may condemn the abuse and downgrade the relations or stop the aid. These political implications might be inherent in the pathology report but should of course not be expressed. The report must be objective and without political views.

Crime is often combined with lack of empathy. The perpetrator does not realise the suffering he is inflicting upon his victim. It is to be hoped that an increased knowledge will decrease the suffering. To that end, the active participation of the pathology profession in the documentation may prove to be a valuable tool.

There has been an increasing awareness of the global need for education in the documentation of human rights abuses. Seminars and workshops have been held in American as well as Asian and African countries. The human rights issue has also entered the medical curriculum in many universities.

Finally, the necessity of scientific research into these dire issues should be emphasised.

1 Doctors, ethics, and torture, proceedings of an international meeting, Copenhagen, August 1986, organized jointly by the Danish Medical Association and the International Rehabilitation Center for Torture Victims. Dan Med Bull 1987;34:185-216.

2 Amnesty International. Prescription for change. Health professionals and the exposure of human rights violations. London: Amnesty International, 1996.

3 Larrain FR. Doctor torturers penalised by their professional body in a country where torture is practised. Dan Med Bull 1987;34:191-2.

4 British Medical Association. Involvement of doctors in torture. Lancet 1986;1:628-9.

5 Vesti PB. Extreme man-made stress and anti-therapy. Doctors as collaborators in torture. Dan Med Bull 1990;37: $466-8$.

6 Danielsen L, Berger P. Torture sequelae located to the skin. Acta Derm Venereol 1981;61:43-6.

7 Thomsen HK. Electrically induced epidermal changes. A morphological study of porcine skin after transfer of low-moderate amounts of electrical energy [disp.]. Copenhagen: FADL, 1984

8 Karlsmark T, Danielsen L, Thomsen HK, et al. Tracing the use of torture: electrically induced calcification of collagen pig skin. Nature 1983;301:75-8.

9 Jacobsen H. Electrically induced deposition of metal on the human skin. Forensic Sci Int 1997;90:85-92.

10 Petersen HD, Vedel OM. Assessment of evidence of human rights violations in Kashmir. Forensic Sci Int 1994;68:10315.

11 Pounder DJ. Documenting and interpreting injuries. Torture 1999;9:15-16.

12 Binz MT. Forensic investigation of past human-rights violations. Lancet 1991;337:1594.

13 Turner B, Wiltshire P. Experimental validation of forensic evidence: a study of the decomposition of buried pigs in a heavy clay soil. Forensic Sci Int 1999;101:113-22.

14 Thomsen JL, Gruschow J, Stover E. Medicolegal investigation of political killings in El Salvador. Lancet 1989;1: 1377-9. 